\title{
Modernismo y postmodernismo, hacia la construcción de un liderazgo antropocéntrico
}

\author{
Mendoza de Ferrer, Hermelinda*
}

\begin{abstract}
Resumen
Este artículo parte de una investigación documental, la cual se adecua a un diseño de tipo bibliográfico con enfoque hermenéutico. Pretende describir algunas teorizaciones relativas al liderazgo ubicándose para ello en los enfoques modernistas y postmodernistas que han servido de modelo para interpretar la realidad, con la finalidad de identificar en cada uno la concepción que del mismo se tiene y, en consecuencia, el rol que el líder debe desempeñar, así como el lenguaje que adopta para alcanzar los objetivos planteados. Como resultado se elabora una propuesta de liderazgo cuyo centro es el ser humano. Las conclusiones a las que se arriba sostienen que, ante el quiebre del modo de pensar modernista, no resuelto por los argumentos postmodernistas, se requiere un retorno a los referentes básicos: el hombre y sus principios y con ello un liderazgo centrado en la persona humana integral dotada de cuerpo y espíritu.
\end{abstract}

Palabras clave: $\quad$ Liderazgo, Antropocéntrico, Modernismo, Postmodernismo.

\section{Modernism and Postmodernism, Toward the Construction of Anthropocentric Leadership}

\begin{abstract}
This article begins with a documentary investigation, which adapts to a design of the bibliographical type with a hermeneutic focus. It intends to describe some theorizations relative to leadership, placing itself for that in the modernist and postmodernist approaches that have served as models for interpreting reality, in order to identity in each one the concept it has of itself, and, consequently, the role the leader ought to play, as well as the language the leader adopts in order to reach the ex-

Recibido: 02-05-06. Aceptado: 02-05-08

* Licenciada en Relaciones Industriales. Especialista en Docencia para la Educación Superior. Magíster en Administración del Trabajo y Relaciones Laborales. Doctora en Ciencias Administrativas. Profesora Titular en la Escuela de Administración y Contaduría Pública de la Universidad de Carabobo. Acreditada en el Programa Promoción al Investigador (PPI).
\end{abstract}


Modernismo y postmodernismo, hacia la construcción de un liderazgo antropocéntrico Mendoza de Ferrer, Hermelinda

pressed objectives. As a result, a proposal for leadership is put forth whose focus is the human being. The conclusions reached sustain that, in the light of the breakdown of the modernist way of thinking, not resolved by postmodernist arguments, a return to basic referents is required: to man and his principles and with that, to a leadership centred on the integral human person gifted with body and spirit.

Key words: Leadership, anthropocentric, modernism, postmodernism.

\section{Introducción}

Los paradigmas, al igual que las organizaciones, nacen crecen hasta llegar a su madurez y comienzan a decrecer, a menos que se produzcan innovaciones que impulsen nuevas curvas de crecimiento. Cuando un paradigma llega a su plenitud y los nuevos patrones de pensamientos comienzan a emerger se produce una pugna entre las ideas del paradigma preexistente y las correspondientes al paradigma emergente, aparece entonces el conflicto, el caos y la confusión, tan característicos del mundo de hoy.

Los directivos de las organizaciones actuales se enfrentan con una realidad altamente compleja devenida, entre otras causas de la situación de transitoriedad que les ha correspondido vivir; para cuyo manejo la experiencia ya no es una guía útil para tomar decisiones acerca de la forma de afrontarla adecuadamente. En este contexto, las organizaciones buscan cada vez más gerentes que muestren cualidades de liderazgo efectivo, esto es, que manifiesten el comportamiento adecuado en el momento oportuno, con una óptima inversión en recursos para la consecución de las metas organizacionales y satisfacción de necesidades.

Sin embargo, las teorías relativas al liderazgo dan cuenta de diversos enfoques respecto al rol que debe desempeñar y las vías para lograr los objetivos, ra- zón por la cual nos planteamos describir algunas teorizaciones relativas al liderazgo ubicándonos para ello en los enfoques modernistas y postmodernistas que han servido de modelo para interpretar la realidad, con la finalidad de identificar en cada uno la concepción que del mismo se tiene y, en consecuencia, el rol que el líder debe desempeñar, así como el lenguaje que adopta para alcanzar los objetivos planteados.

En atención a este direccionamiento de logro, el trabajo se estructuró considerando algunas tipificaciones del liderazgo para luego indagar acerca de su conceptualización en la cultura moderna y postmoderna, sus contrastes y tendencias, todo ello enmarcado en un diseño de investigación de tipo bibliográfico con enfoque hermenéutico que involucró la interpretación de diversos autores permitiendo, a través de su triangulación, darle sentido a las informaciones recabadas del texto escrito, a fin de generar una construcción teórica que aproxime a la realidad de los cambios en el ámbito del liderazgo.

\section{Algunas tipificaciones de liderazgo}

Con el paso de la modernidad a la postmodernidad (Schvarstein, 1998), se produce un cambio de la concepción del capital como principal recurso hacia el poder del conocimiento y la importancia 
de la información y del ser humano para lograr competitividad, de las organizaciones jerárquicas y piramidales hacia las organizaciones en red o de tipo circular, del trabajo individualizado al trabajo en equipo, del liderazgo en manos de una sola persona al liderazgo compartido, o como lo denomina Senge y otros (2000), "el liderazgo de la comunidad". Según Márquez (2001), se están dando procesos de ruptura y quiebre en diferentes campos de la realidad social, de lo cual no escapa el mundo de las organizaciones.

En el ámbito del liderazgo, Senge y otros (2000), considera líder a toda persona que desempeña papeles críticos para generar y mantener "tensión creativa", independientemente del nivel ocupado en de la organización, por consiguiente, identifica tres tipos de líderes, a saber: 1) Líderes Locales de Línea o personas con responsabilidad por los resultados y autoridad para realizar cambios en la organización y ejecución del trabajo; 2) Líderes de Intercomunicación. o trabajadores de la red informal de información interna, también denominados creadores de comunidad, 3) Líderes Ejecutivos, aquellas personas con responsabilidad global por los resultados del negocio e impulsoras de cambios.

Según Kets de Vries y FlorentTreacy (1999), para hacer frente a un mundo en rápido y continuo cambio, como el que se está viviendo, las organizaciones deben contar con líderes con aptitudes relacionales, por cuanto que, la mayor parte del trabajo del liderazgo supone inspirar, motivar y movilizar a las personas a actualizar su visión específica de futuro. Se trata de crear el futuro a partir de su visualización, para luego planificar y llevar a cabo las acciones que permitan hacerlo realidad, con el concurso de quienes participaron en su concepción.

Sin embargo, esto exige un proceso de formación que debería incluir cuatro momentos en constante retroalimentación, como son: Diagnóstico, Planeación, Ejecución y Evaluación y Seguimiento en el que cada etapa esté apoyada en los subsistemas de recursos humanos que, a su vez, forman parte del sistema socioestructural, que es justificado por el sistema cultural específico de la organización en la cual se desarrolla (Mendoza, 2007).

Este proceso implica que la cultura organizacional traspasa la organización dando a sus integrantes un conjunto de significados compartidos que orienta sus acciones e indica cómo se hacen las cosas allí, disminuyendo las tensiones, atribuyéndole sentido a lo que sucede y mostrando el camino a seguir. Ahora bien, la cultura, como producto social, no puede ser un hecho aislado de la sociedad, ésta la impacta y al mismo tiempo es impactada por ella, construyendo significados y reconstruyéndose constantemente.

Cada cultura y cada sociedad responden a un modo de pensar y conocer específico que define su racionalidad, convirtiéndose en el cauce por donde circula todo el proceso, dando lugar a los paradigmas que establecen para sus integrantes las señales bajo las cuales se inician las investigaciones en los diferentes campos académicos. Con todo, los paradigmas no son permanentes y cuando comienzan a cambiar, se empiezan a cuestionar los supuestos básicos y las metodologías del campo de estudio correspondiente (Kunt, 1971), con la consecuente pérdida de confianza en la racionalidad 
Modernismo y postmodernismo, hacia la construcción de un liderazgo antropocéntrico Mendoza de Ferrer, Hermelinda

imperante, afirmación aplicable a los estudios sobre el liderazgo (Chaves, 1999).

En efecto, la cultura, en cierto modo, determina el perfil del líder requerido por cada sociedad u organización y, simultáneamente, el líder puede superarlas y modificarlas mediante una práctica creadora; su acción surge en el seno de una cultura donde va a tratar de expresar, exteriorizar y pronunciar sus ideas a través del lenguaje -como elemento de esa cultura- y es en el seno de esa cultura donde el liderazgo se ha ido movilizando desde una búsqueda de sus rasgos comunes para intentar reproducirlos en aras de alcanzar los objetivos organizacionales, "hacia el poder del conocimiento determinando nuevas formas de actuación ligadas a diversas identidades asociadas al ser humano y su potencial creativo" (Mendoza y Rodríguez, 2007:169), que demanda un liderazgo capaz de fomentar las virtudes morales y poner su carisma al servicio de la sociedad y los demás (Robbins, 2004), esto es, un liderazgo antropocéntrico, centrado en el hombre, sus auténticas necesidades y el respeto a su dignidad, para lo cual un elemento clave es el diálogo respetuoso del interlocutor donde, sin menoscabo de los valores propios, debe prevalecer la inviolabilidad de cada persona como requisito indispensable para lograrlo.

Siguiendo a Juárez (2005), es un liderazgo que negocia, abierto al diálogo, cuya forma de conducir y orientar implica la aceptación del grupo por ser coherente, viable y bueno para los demás. Un líder que no se reconoce como sujeto de intereses personales sino como miembro de una gran comunidad, orientado a la consecución del bien personal y sobre todo social. Sin olvidar -parafraseando a Pérez (2007), la responsabilidad de cada uno para con los derechos del otro como núcleo ético del comportamiento organizacional.

Por lo hasta aquí expuesto, abordar el estudio del liderazgo implica ubicarse en los enfoques modernistas y postmodernistas que han servido de modelo para interpretar la realidad e identificar en cada uno la representación que del mismo se tiene y, en consecuencia, el rol que debe desempeñar, así como el lenguaje adoptado por el líder para alcanzar los objetivos planteados, según de la Garza (2008), probablemente ya no en términos de progreso sino de juegos lingüísticos o de poder.

\section{Modernismo y liderazgo}

En la concepción modernista, sociedad en la cual la razón se considera única e invariable (de la Garza y otros, 2008), se otorga gran dignidad a la racionalidad individual, la capacidad de observación cuidadosa y deliberación racional; pauta que guió el discurso durante el siglo XX (Gergen y Tojo, 1996). En la modernidad el estudio del liderazgo se inicia con la teoría de los Rasgos cuyo objeto era identificar en los líderes las características de personalidad dominantes. Posteriormente se estudió su comportamiento a fin de precisar las conductas propias del liderazgo, que pudiesen ser enseñadas en la formación de líderes.

Luego se comenzó a tomar en consideración las contingencias que enmarcaban la necesidad de liderazgo. Se consideraba líder ideal a quien era capaz de adecuar su estilo a las demandas de la si- 
tuación, determinadas por la tecnología, la cultura o la madurez de los subordinados, según fuese el caso. Predominaba la idea de que se podía conducir la organización a través del desarrollo de las capacidades racionales impulsándose las investigaciones hacia la concepción estratégica. Se consideraba que el poder del pensamiento racional capacitaba al hombre, y en consecuencia al líder, para lograr su perfeccionamiento $y$, a través de acciones específicas institucionalizadas, era posible seleccionar los medios más convenientes para alcanzar los objetivos establecidos (Val Pardo De, 1998).

Otra herencia del discurso modernista es su énfasis en la observación. Se presume que existe una realidad organizacional concreta, un mundo objetivo, capaz de estudio empírico. Se describe a las organizaciones como seres vivientes con propiedades típicas del mundo biológico. Se enfatiza la necesidad de la organización para obtener información sistemática, hechos o datos para optimizar la toma de decisiones (Gergen y Tojo, 1996). Haciendo una inferencia de lo planteado por este autor, puede afirmarse que se privilegia la voz del líder si éste es un experto en observación rigurosa y si ésta suministra información esencial a la organización, un buen ejemplo de ello puede ser el Liderazgo Centrado en Resultados que busca cerrar la brecha existente entre los atributos del líder y los resultados obtenidos (Ulrich y otros, 1999).

El tercer aspecto que Gergen y Tojo (1996), aíslan en la caracterización del modernismo, es la lengua como representación cuyo énfasis está en su concepción como expresión externa de la mentalidad y medio por el cual se informa a los colegas y a la sociedad los resultados de las observaciones y pensamientos. Las palabras del líder son portadoras de la verdad o del conocimiento. Adicionalmente existe la creencia de que si la razón y la observación son armónicas y la naturaleza del mundo objetivo son hechos conocidos por la lengua, los líderes pueden examinar nuevamente y avanzar para alcanzar un conocimiento cada vez más sofisticado que contribuya al mejoramiento continuo de la organización, hasta niveles de utopía, denominado "crecimiento estable", como idea de progreso.

Desde la óptica modernista, la discusión racional debe pasar por las reglas existentes dentro de una tradición particular cultural, dándose jerarquías de racionalidad dentro de la cultura, en virtud del grado educativo y nivel cultural, entre otros, por ello, algunos individuos son considerados más racionales que otros y así más dignos de mando, posición y riquezas. Por ello, los que ocupan las mas altas posiciones generalmente son provenientes de un pequeño sector de la población, dando lugar a estructuras de dominación y poder (Gergen y Tojo, 1996).

Desde la perspectiva ofrecida por Light (1991), esto es así, por cuanto que, a través del proceso de socialización, las personas provenientes de sectores mas privilegiados han podido desarrollar un código elaborado de conversación que viene a ser el lenguaje de la persuasión, de la diferenciación y de la explicación. El liderazgo adopta de esta forma un enfoque transaccional producto de la interacción entre líder y los seguidores, cuya máxima expresión podría ser el Liderazgo Carismático, según el cual el líder tiene la capacidad de concebir una visión 
Modernismo y postmodernismo, hacia la construcción de un liderazgo antropocéntrico Mendoza de Ferrer, Hermelinda

enaltecedora, transmitirla a sus seguidores, hacerlos sentir capaces de alcanzarla y estimularlos cuando se acercan a ella (Conger, 1991).

En esta trama, la organización eficaz sería aquella donde varios grupos de especialistas generan datos relevantes para sus funciones particulares; los resultados son canalizados a otros niveles de la jerarquía organizacional y el líder formal, de mayor jerarquía, es informado para la toma racional de decisiones y la coordinación de actividades. La lengua viene entonces a ser una expresión de la racionalidad reinante en este contexto que enfatiza la racionalidad y el empirismo, siendo la que puentea hacia el pensamiento postmoderno (Gergen y Tojo, 1996).

Durante la Modernidad el liderazgo convivió con la ilusión de poseer la verdad y construyó un mundo de racionalidad independiente e indiferente de la realidad humana. La revolución de las comunicaciones y el proceso de globalización, entre otros, condujeron a la duda postmoderna; la modernidad, el mundo creado por la razón, parece ahora insuficiente, "pero anclados todavía en él nos sentimos incapaces de superarlo... La modernidad se nos queda, pues, pequeña pero buscamos una substitución desde los mismos presupuestos que la hacen insuficiente. Hemos perdido el referente originario y se hace imperativo recuperarlo para encontrar en él una nueva pauta de conocimiento: la posibilidad de diálogo" (Gómez-Martínez, 1999). De acuerdo con Juárez (2005), es ineludible formarse para la tolerancia y el diálogo o, según Meszaros (2006:26), para la paz pues "hay demasiada alteración de la conciencia", situación que amerita cambiar el "viejo software mental" heredado de la modernidad y, a juicio de Zamora y Poriet (2006) -para dirigir las organizaciones del siglo XXI- seres integrales, emprendedores, gestores y líderes, así como, la metanoia de gerente a líder.

\section{Postmodernismo y concepción del liderazgo}

Pareciera existir consenso de que el juego de interrelaciones y creencias modernistas pierde poco a poco su sentido de ordenamiento y validez. Ha surgido una nueva forma de interpretación de la realidad, predominantemente crítica, que está desmontando sistemáticamente las posiciones modernistas. Según Gergen y Tojo (1996), en el contexto postmoderno el concepto de racionalidad es considerado opresor, se pasa del individuo racional a la racionalidad comunal, se critica a la lengua como expresión de la racionalidad y se le conceptúa como un sistema de significados que tanto preceden como sobreviven al individuo pues la discusión racional debe tomar en consideración las formas de lenguaje enmarcadas dentro de las relaciones culturales en las cuales se produce.

Así, en el pensamiento postmoderno, la lengua viene a ser un subproducto del intercambio humano y su viabilidad depende de la cooperación vecinal, de allí la necesidad del liderazgo de equipo. En su rol emancipatorio, el argumento del líder selecciona aspectos del mundo dado por sentado; busca demostrar su carácter socialmente construido, invita a formulaciones alternativas e impulsa a la creación de una nueva realidad. En su papel expositivo, intenta aclarar los 
procesos por los que es creada la realidad y sensibilizar en cuanto a la necesidad de participación en la construcción del mundo, acentuando el potencial para el cambio comunitariamente organizado. Además, al invitar a entrar en el proceso de crear la realidad, el lenguaje del líder pasa a ser una fuerza impulsora para la acción.

Afirma Val Pardo (1998) que, si la modernidad se vincula a la industrialización, a la postmodernidad están directamente asociadas la información, el conocimiento y la microelectrónica; sin embargo, para Gómez-Martínez (1999), frecuentemente se confunden los términos por la duda existente ante las transformaciones que están produciendo, cuya difusión se acelera por las tecnologías de información, deconstruyendo las estructuras de la modernidad que aún fundamentan las instituciones sociales, convirtiéndose en fuente de ambigüedad e incertidumbre.

Considera que la desorientación y caos, que generalmente se respiran en la cultura postmoderna, hacen necesarios nuevos parámetros para reorientar las organizaciones empresariales como pueden ser: la articulación de misión, metas, estrategias y funciones, la institucionalización de la planificación y las comunicaciones, la identificación de mecanismos de coordinación y control y el liderazgo efectivo, entre otros, aspectos que ratifican la necesidad de su ajuste.

Appignanesi y otros (1997) reconocen como problemas propios del arte postmoderno la representación, la reproducción y la legitimación. Veamos cómo podrían estos tres grandes temas ser aplicados al ámbito del liderazgo, proceso organizacional que, según Val Pardo
(1998), debe ser reorientado a fin de responder a la dinámica cambiante de su entorno.

En opinión de López (2001), el comportamiento organizacional, como parte de la práctica mediante la cual el sujeto se produce a sí mismo al construir el sentido de su propia vida, es donde, progresivamente, la estructura política caracterizada por líneas de mando verticales, propia de las organizaciones militares, sobre las cuales se sostenía el liderazgo formal, derivó hacia modelos autocráticos que, al ser penetrados por las prácticas eleccionarias, características de las organizaciones partidistas, dieron origen al centralismo democrático, profundizando la representatividad formal que, con el advenimiento de la postmodernidad, flexibilizó la rigidez de las organizaciones jerárquicas y permitió el surgimiento de modelos de liderazgo abierto y de mayor participación en la forma comunicativa, dialógica y simbólica postmoderna.

En este proceso dialógico el sujeto construye sus propias representaciones que ahora son visiones compartidas, negociadas que regulan su comportamiento dentro de la organización. Por ende, el modo de vida organizacional es ahora un modo de vida comunicacional mediante el cual los equipos logran los consensos para la toma de decisiones y los líderes van adoptando herramientas dialógicas que "potencian la comunicación, facilitan la producción de subjetividad y en consecuencia la formación de la riqueza simbólica" (López, 2001:136). Los recursos son las ideas y la información, siendo estos los que se reproducen en la nueva organización en red, a diferencia de los medios 
Modernismo y postmodernismo, hacia la construcción de un liderazgo antropocéntrico Mendoza de Ferrer, Hermelinda

de producción masiva de la modernidad que conducían a la reproductibilidad del capital.

En palabras de Lanz (2001:162), "Los acomodos y adaptaciones de los procesos organizacionales a las nuevas condiciones de la posmodernizacion de la sociedad obedecen a la pulsión de continuidad (reproducción) que es constitutiva de las prácticas sociales y de sus formas", por lo que buena parte de las reformas organizacionales están asociadas a la dinámica de adaptación de cada espacio a las demandas del conjunto de situaciones que se suceden durante el proceso de la acción comunicativa. Por ende, el liderazgo, como proceso organizacional que comunica al sistema organizacional con los grupos que de él son parte integrante, es influido por las nuevas condiciones reinantes en el paradigma emergente. ${ }^{1}$

Continuando con Lanz (2001:165), la generalización del proceso de "aplanamiento organizacional que se vive en todos lados coexiste con prácticas tradicionales, con métodos despóticos y con mentalidades arcaicas. Ello está asociado a un rasgo cultural de esta transición posmoderna que bulle en la civilización occidental: el destronamiento del <status>, el eclipse de las jerarquías, la deslegitimación de los criterios de autoridad."

Este cambio en las prácticas sociales se manifiesta en el ámbito organizacional, tal es el caso del liderazgo. Se cuestiona la legitimidad del liderazgo formal otorgado por el cargo. Es notoria la tendencia a la desjerarquización de las relaciones sociales y deslegitimación de las instituciones (Zambrano, 2001), comienza a tomar forma el liderazgo de equipo, sometido a legitimación en función de las competencias de quienes lo sustentan, así como, para cultivar las capacidades potenciales de la organización y sus integrantes.

Parafraseando a Lanz (2001:170), puede afirmarse que los procesos organizacionales no son ajenos al impacto del paradigma postmoderno, al contrario, las organizaciones son un terreno fértil para que cristalicen los nuevos contenidos, donde lo comunicacional se proyecta "como el nuevo contenido de las formas organizacionales, tanto en el componente informacional de la comunicación, como en las configuraciones estéticas de los medios en desarrollo".

\section{Modernidad y Postmodernidad. Contrastes en el liderazgo}

Para de la Garza (2008:10) a la crisis epistemológica del positivismo acaecida en la década de los setenta, se unen la crisis práctica devenida de la imposibilidad de predicción de grandes teorías sociales, el inicio de la crisis ecológica relacionada con la industrialización, la del es-

1 Martínez (1997) presenta un conjunto de postulados que se constituyen en los elementos clave del paradigma emergente a saber: Tendencia al orden en los sistemas abiertos, ontología sistémica, conocimiento personal, metacomunicación del lenguaje total y principio de complementariedad. 
tado interventor - benefactor y la extensión de la pobreza para convertirse en caldo de cultivo para "la desconfianza como estado de ánimo acerca de la idea de razón, de sujeto transformador y de progreso" en detrimento del imaginario de futuro, de proyecto o de organización, crisis que buscó su salida en el individualismo concebido como libertad frente a estructuras o concepciones totalizantes -consideradas opresoras- sin prever las consecuencias de la fragmentación que traía aparejada y con ello el inicio de su decadencia.

Por su parte, Gergen y Tojo (2004), ante lo que describen como el desequilibrio producido por el quiebre del modo de pensar modernista, visualizan el reemplazo de la deliberación racional por racionalidad comunal, del conocimiento empírico por la construcción social, y la lengua como representación por la lengua como acción. En cambio, GómezMartínez (1999) propone un diálogo entre seres humanos, con expresiones anteriores a toda contextualización que implica al ser humano como referente original, haciendo posible un discurso cognoscitivo, en una dimensión antrópica que supera el diálogo depositario de la modernidad y la negación postmoderna sobre la universalidad del discurso humano.

Desde esta perspectiva, el lenguaje del líder emerge en el seno de una lengua o estructura externa convencional de signos que lo aprisionan y, en cierto modo, lo determinan; el error y la verdad de su discurso son indiferentes e independientes del sujeto que los percibe, superando la negación postmoderna relativa a la posibilidad de comunicación ajena a un contexto cultural, pues, expresiones de alegría, tristeza o un grito de pánico hablan de un diálogo entre seres humanos a través de su referente raíz, algo anterior al símbolo como elemento cultural, con todo, de la Garza (2008), reporta, junto a la transformación ocurrida entre los setenta y los ochenta, la emergencia de antiguos y nuevos grandes discursos y la inviabilidad del programa postmoderno extremista.

En el discurso de la modernidad, el otro es juzgado desde la propia contextualización y no se considera la existencia de un discurso diferente; la reconstrucción postmoderna, reconoce el discurso del otro, pero éste no es tomado en consideración, ambos son independientes. En el discurso antrópico, el otro "pasa a ser un punto más en la contextualización de mi discurso y, como tal, esencial al momento de pronunciarme: el discurso antrópico asume la otredad como paso previo al acto de significar" (Gómez-Martínez, 1999).

Si se aplican estas afirmaciones al ámbito del liderazgo podría decirse que el líder moderno no toma en consideración a sus seguidores convirtiéndolos en instrumentos para alcanzar sus objetivos, el postmoderno se abre hacia esquemas de participación al comunicar a sus seguidores las metas a alcanzar, escuchando sus sugerencias para lograrlas, aunque las metas personales y las metas organizacionales son independientes; en consecuencia, sus decisiones ignoran "la otredad", representada por los seguidores, y no cuentan con ella.

Se produce una transformación en la concepción del liderazgo cuando aparece el chip que da lugar a los avances en el área de la microelectrónica que ha logrado modificar no sólo las formas de pro- 
Modernismo y postmodernismo, hacia la construcción de un liderazgo antropocéntrico Mendoza de Ferrer, Hermelinda

ducción, sino el pensamiento estratégico. La búsqueda de mayor competitividad se abre nuevos caminos a través de la innovación, el mejoramiento continuo y la capacidad de aprendizaje, siendo esto sólo posible con el concurso del ser humano (Senge y otros, 2000), (Swieringa y Wierdsma, 1995), pasando el talento humano a ser el verdadero capital con que cuenta la organización para lograr mayor competitividad. Sin embargo, de la Garza (2008:14), acuña el término para - post modernidad cuya característica básica es la fragmentación y con ella "la desestructuración de las relaciones de trabajo que, al ser cambiantes, no habría claridad en los grupos de pertenencia." De donde se desprende la necesidad de fortalecer las funciones de integración organizacional a fin de contrarrestar la falta de lealtad, la no confianza, la angustia y la frustración.

Por lo hasta aquí expuesto, el progreso o idea de bienestar ha sido una promesa no cumplida en ambas épocas -modernidad y postmodernidad- el líder como guía que conduce hacia dicho propósito no ha podido lograr los resultados esperados en cuanto al beneficio colectivo se refiere, aunque reconoce a sus seguidores, se centra en la construcción que hace de su realidad, pues todavía es gobernado por estructuras de la modernidad, tambaleantes ante una realidad que se torna cada vez más inestable.

Razón por la cual Gómez-Martínez (1999) considera que, en la actualidad, se impone una dimensión antrópica donde la decodificación del discurso se caracteriza por lo dinámico de su centro o el referente del cual parte; es decir, el proceso de codificación que fundamenta las estructuras que hacen posible el discurso es dinámico; así como en el pasado se trasladó el centro del universo de la tierra al sol, ya los colaboradores no giran alrededor del líder, por el contrario, el liderazgo gira alrededor del equipo y, en forma más específica, de aquel que, según la realidad que están enfrentando, posee las mejores competencias para al logro de objetivos compartidos. Dicho en otras palabras, el centro o referente raíz es contextualizado en el tiempo y en el espacio, individual y socialmente, al reconocer los aspectos individual y social, propios de los enfoques modernos y postmodernos, respectivamente.

Esta dimensión asume un enfoque reflexivo y dinámico que posibilita la comunicación. Trata de aproximarse al ser humano a partir de la ruptura con el discurso de la modernidad que mira al otro como simple depositario de la verdad del líder, para abrir paso a una relación dialógica, asumiendo las herramientas de comunicación de ambos paradigmas, al observar los cambios desde afuera para luego sumergirse en ellos y vivir sus altibajos, sin perder de vista las estructuras existentes en diversos puntos del contexto. En el ámbito del liderazgo, ello implicaría reconocer la fuerza generativa que tienen las palabras que hace del lenguaje una acción, sin olvidar la relación interpersonal y el dinamismo que conduce a la construcción de la realidad.

Ahora bien, ¿puede un líder sumergirse en la vorágine del cambio y no perder el sentido sin que su ser esté sólidamente construido?, ¿será capaz de presentarse al otro como es en realidad, con sus aspectos positivos y negativos, pero consciente de que tiene enormes posibilidades y que puede, contando con los 
otros, llegar a realizar en gran parte su ideal para no dejar atrofiada una parte esencial de su yo potencial y ayudar a que ellos también desarrollen su máximo potencial, respetando su dignidad de seres humanos? Dar respuesta a estas interrogantes implica un nivel de profundidad que desborda el ámbito de este artículo, sin embargo, en las líneas siguientes se esbozan algunos aspectos dignos de ser tomados en consideración.

\section{Hacia un liderazgo centrado en el hombre}

En la introducción de este artículo se planteó el conflicto existente como consecuencia del cambio de paradigmas, hoy la paz es más buscada que nunca, sin embargo, la conflictividad está a la orden del día, la ruptura paradigmática está socavando las bases estructurales de la sociedad produciendo desequilibrios difíciles de subsanar desde el sistema de pensamiento racional al que estamos acostumbrados; $y$, así como la sociología nació de las inquietudes de un grupo de estudiosos que intentaban recuperar el orden perdido, con el advenimiento de la modernidad (Ritzer, 1993), surgen propuestas tales como la Programación Neurolingüística, la Inteligencia Emocional, la Semiótica y el Liderazgo Centrado en Principios que intentan dar respuesta a la realidad que estamos confrontando.

Appignanessi y otros (1997), visualizan, para el final del juego postmoderno, el retorno del pensamiento de los filósofos de la "Gran Narrativa", entre ellos, Kant, Hegel y Marx y la reaparición del Romanticismo, como aquello que tal vez pueda traernos el remedio que busca- mos. Desde otro ángulo, el capítulo 16 del Tao de la Paz reza "Ahora bien, las cosas muchas y diversas vuelven todas a sus raíces. Volver a la raíz se llama tranquilidad, y se llama retornar al propio destino" (Wang Chen, 2000:183), es decir, todas las cosas vivas vuelven a sus raíces con el fin de conservar su tranquilidad. Cada una consigue volver a su naturaleza a fin de ceñirse adecuadamente a las divisiones naturales para alcanzar el Tao verdaderamente, que es obtener la sabiduría y la felicidad plena.

Para Juan XXIII (1963), las leyes que rigen las relaciones entre los individuos hay que buscarlas, solamente, en la naturaleza del hombre. A través de su dignidad intrínseca éste puede descubrir el orden que impera en los seres vivos y en las fuerzas de la naturaleza y forjar los instrumentos adecuados para adueñarse de esas fuerzas y ponerlas a su servicio. Siendo estas leyes las que enseñan claramente a los hombres cómo deben regular sus mutuas relaciones en la convivencia humana. Cuando esta convivencia se ordena al respeto de los derechos y los deberes, los hombres se abren inmediatamente al mundo de las realidades espirituales, comprenden la esencia de la verdad, de la justicia, de la caridad, de la libertad, adquieren conciencia de ser miembros de tal sociedad y se sienten impulsados a la trascendencia.

En el mismo orden de ideas, el líder debe dictar aquellas disposiciones que, además de su perfección formal, se ordenen por entero al bien común o puedan conducir a él. La razón de ser de cuantos lideran debe radicar por completo en ese bien común el cual está íntimamente ligado a la naturaleza humana, por tanto, 
Modernismo y postmodernismo, hacia la construcción de un liderazgo antropocéntrico Mendoza de Ferrer, Hermelinda

abarca a todo el hombre, es decir, tanto su parte corpórea como su parte espiritual. Añádase a esto que todos los miembros de la comunidad deben participar en el bien común por razón de su propia naturaleza, aunque en diversos grados, según las categorías, méritos y condiciones de cada uno. Por lo que los líderes han de orientar sus esfuerzos a que el bien común redunde en provecho de todos, sin preferencia por persona alguna o grupo social determinado.

Dado que el bien común consiste principalmente en la defensa de los deberes y derechos de la persona humana, la misión principal del líder debe tender a dos cosas: de un lado, reconocer, respetar, armonizar, tutelar y promover tales derechos; de otro, facilitar a cada seguidor el cumplimiento de sus respectivos deberes. Sin embargo, teniendo en cuenta que las relaciones entre los seres humanos y de estos con las instituciones resultan tan inciertas, complejas y hasta peligrosas, el líder debe poseer una recta idea de la naturaleza de sus funciones y de los límites de su competencia, unidos a un sentido de la equidad, integridad moral, agudeza de ingenio y constancia de voluntad en alto grado para descubrir sin vacilación lo que hay que hacer y para llevarlo a cabo a tiempo y con valentía.

Lo anterior implica que el liderazgo debe estar supeditado a los principios, como todos los hombres son entre sí iguales en dignidad natural, ninguno de ellos, en consecuencia, puede obligar a los demás a tomar una decisión en la intimidad de su conciencia, por tanto, el seguimiento a un líder no es sometimiento de hombre a hombre sino un acto producto de su conciencia. Por ejemplo, cuando los gobernantes promulgan una ley o una disposición contraria a los principios del ciudadano, ni la ley promulgada ni la disposición dictada pueden obligarlo en conciencia, ya que, por encima de los hombres se encuentran los principios.

La razón exige que los líderes, teniendo muy en cuenta los designios de su conciencia, se consagren a la acción temporal, conjugando plenamente las realidades científicas, técnicas y profesionales con los bienes superiores del espíritu. Es necesario que se de en ellos la unidad del pensamiento y la voluntad, de tal forma que su acción quede iluminada por sus principios. Deben estar convencidos de que lo hasta ahora hecho no basta para lo que las necesidades piden, y, por tanto, deben acometer cada día empresas de mayor volumen y más adecuadas en los diferentes campos que le competen. Deben estar convencidos de que la paz verdadera y constante no puede apoyarse en el equilibrio de las fuerzas, sino únicamente en la confianza recíproca. Las relaciones deben regirse no por la fuerza de las armas sino por las normas de la recta razón, es decir, las normas de la verdad, de la justicia y de una activa solidaridad.

Para Juan XXIII (1963), la paz no se puede dar en la sociedad humana si primero no se da en el interior de cada hombre. Para este Papa la paz será palabra vacía mientras no se funde sobre un orden basado en la verdad, establecido de acuerdo con las normas de la justicia, sustentado y henchido por la caridad y, finalmente, realizado bajo los auspicios de la libertad y reafirma la Gaudium et Spes (1966:78) "la paz jamás es cosa del todo hecha, sino un perpetuo quehacer...el cuidado de la paz reclama de cada uno 
constante dominio de sí mismo y vigilancia por parte de la autoridad legítima". En línea con estas ideas está la crítica de Aguiar (2000: 121-122), sobre la tendencia antropocentrista emergente como producto del cambio global, la cual se reproduce a continuación.

La ausencia de la vieja institucionalidad...revierte nuestra mundanidad hacia el antropocentrismo, con mengua de lo estructural; y los signos y su contenido no predican ser, ciertamente, los más representativos de la vocación humana. En otra palabras, todos y el todo regresan hacia el hombre como tal y en cuanto centro y explicación que es de la vida y de la vida misma en sociedad; más la tendencia de marras también intenta fraguar una cultura proclive a la negación del hombre en su ser y en la razón metatemporal de su libertad. Lo cual, a fin de cuentas, no hará otra cosa que abrirle cauces propicios a renovadas formas de dominación y esclavitud humanas. Se hace impostergable, por ende, una nueva justificación y reconstrucción de lo social a partir del propio hombre, en su dual dimensión: como individuo y como persona; como ente uno y único, pero carente, necesitado de los otros y de suyo convocado a la alteridad; $y$ también, como hacedor y sujeto del orden humano.

Desde esta óptica, un liderazgo antropocéntrico, necesariamente, tiene que partir del respeto a la dignidad humana, en contraste con la corriente que se revela en la mundialización de las exclusiones promovida por el libre mercado y la universalización de "la moral de los egoísmos". Es un liderazgo que debe comenzar por liderarse a sí mismo, respetar su propia dignidad para estar en capacidad de darse a los demás con vocación de servicio. En este sentido, la Tertio Millenio Adveniente, indica "A la crisis de civilización hay que responder con la civilización del amor, fundada sobre valores universales de paz, solidaridad, justicia y libertad..." (Juan Pablo II, 2000:52). Un líder capaz de, conociéndose ayudar al otro a conocerse y desarrollar su máximo potencial para ponerlo al servicio de la construcción de un mundo más humano y más justo.

Otro autor que plantea la idea del servicio es Hunter (1999:35), quien define el liderazgo como "el arte de influir sobre la gente para que trabaje con entusiasmo en la consecución de objetivos en pro del bien común". Para este autor líder es aquel que identifica y satisface las legítimas necesidades de su gente y quita todo obstáculo para que pueda servir al cliente, por lo que propone el modelo de la Pirámide Invertida como símbolo del liderazgo de servicio.

Según este modelo, el liderazgo que perdura en el tiempo debe estar fundado en la influencia, a la que el autor denomina autoridad. La autoridad siempre se funda en el servicio, o en el sacrificio por aquellos a los que se dirige, que a su vez consiste en la identificación y satisfacción de sus legítimas necesidades y, el servicio y el sacrificio se fundan en el amor, entendido como verbo que describe un comportamiento. El amor es una decisión, por ello se funda siempre en la voluntad, es decir, afectividad con efectividad.

De esta forma, el liderazgo empieza con la voluntad. Con la voluntad adecuada se elige amar que lleva implícita la decisión de identificar y satisfacer las le- 
Modernismo y postmodernismo, hacia la construcción de un liderazgo antropocéntrico Mendoza de Ferrer, Hermelinda

gítimas necesidades de los que se dirigen. Al identificar y satisfacer sus necesidades les estamos sirviendo y sacrificándonos por ellos. Cuando les servimos y nos sacrificamos estamos forjando nuestra autoridad o influencia y cuando se forja la autoridad sobre la gente se gana el derecho a ser llamado LIDER, según el referido autor, un ejemplo de liderazgo de servicio es Jesús de Nazareth, cuya influencia dura hasta nuestros días; fue un liderazgo de servicio y sacrificio al extremo de morir en la cruz, en un acto de amor para hacer la voluntad del Padre.

\section{Conclusiones}

El liderazgo no escapa a los efectos de los cambios actualmente confrontados. Si bien la cultura y la estructura de la sociedad influyen en el estilo de liderazgo considerado apropiado, según la situación, el líder puede interpretar esa realidad a partir de sus principios, reconstruirla, proyectarse hacia el futuro e impulsar las acciones necesarias para hacerlo realidad, en un proceso creador, con el concurso de la comunidad, así, al invitar a entrar en el proceso de crear la realidad, su lenguaje pasa a ser una fuerza impulsora para la acción, sin perder de vista que, lo que somos se transmite con mayor elocuencia que lo que decimos.

En la concepción modernista se da gran importancia a la racionalidad individual y la observación cuidadosa, y la lengua es la expresión externa de la mentalidad. Se mostró cómo estas ideas han estado presentes en la representación de las organizaciones, y en forma más específica, en la conceptualización del liderazgo como proceso organizacional, según esto las teorías del Liderazgo Centrado en Resultados y Liderazgo Carismático son buenos exponentes de un liderazgo de corte transaccional, como expresión de la deliberación racional.

La ilusión de poseer la verdad y el mundo objetivo de la modernidad han sido fuertemente impactados por el cataclismo producido por la revolución de las comunicaciones, el avance del conocimiento y el proceso de globalización, entre otros, conduciendo a la duda postmoderna y al cuestionamiento del mundo creado por la razón, en el cual aún nos mantenemos pues buscamos su substitución desde los mismos presupuestos que lo hacen insuficiente. La desorientación y caos, propios de la cultura postmoderna, impulsa a reorientar las organizaciones mediante nuevos mecanismos como pueden ser: la articulación de misión, metas, estrategias y funciones, la institucionalización de la planificación y las comunicaciones, la identificación de mecanismos de coordinación y control y el liderazgo, entre otros. Por lo que se consideran acertados los planteamientos en torno al liderazgo de la comunidad, liderazgo de servicio y la necesidad habilidades relacionales para su ejercicio en el mundo de hoy.

Se asumió la representación, la reproducción y la legitimación como problemas propios del postmodernismo, aplicables al ámbito del liderazgo, proceso organizacional que debe ser reorientado a fin responder a la dinámica cambiante de su entorno. En este sentido, se observa que, con el advenimiento de la postmodernidad, se flexibiliza la representatividad del liderazgo formal, moviéndose hacia modelos de liderazgo abierto y de mayor participación que adoptan la forma comunicativa, dialógica y simbólica. 
En ese proceso dialógico los recursos son las ideas y la información, siendo estos los que se reproducen en la nueva organización en red, a diferencia de los medios de producción masiva de la modernidad que conducian a la reproductibilidad del capital; también, se cuestiona la legitimidad del liderazgo formal otorgado por el cargo, emergiendo el liderazgo de equipo, constantemente sometido a legitimación en función de las aptitudes de quienes lo sustentan, considerándose básicas para alcanzar el éxito la capacidad de aprendizaje y la competencia comunicativa.

Ante el desequilibrio producido por el quiebre del modo de pensar modernista, no resuelto por los argumentos postmodernistas con sus crisis de sentido, se propone un retorno a los referentes básicos: el hombre y sus principios y con ello un liderazgo antropocéntrico o centrado en el ser humano como ser integral dotado de cuerpo y espíritu. Se hace impostergable una nueva justificación y reconstrucción de lo social a partir del hombre, en su doble dimensión: mente y espíritu, con lo cual estamos refiriéndonos a la necesidad de un cambio cultural que permita contrarrestar los efectos negativos de ambas racionalidades mediante el aprendizaje de nuevas competencias para el trabajo y las relaciones sociales.

\section{El tú, el yo y el nosotros del liderazgo ¿Una propuesta?}

Parafraseando a Hortelano (1989: 151), desde el punto de vista fenomenológico, el liderazgo es un encuentro interpersonal del yo con el tú para construir un nosotros, donde si el tú me ayuda a des- cubrir lo que yo estoy llamado a ser, lo que soy capaz de pensar y de hacer, es legítimo y normal que lo siga, que suspenda mi existencia de la suya, que acepte su influencia. Ahora bien, ese nosotros no puede limitarse a mirar juntos en la misma dirección. "La verdad tiende necesariamente a convertirse en vida, compromiso interpersonal", es decir, no se trata sólo de descubrir el futuro que juntos pueden lograr y las posibilidades que para ello se poseen, hay que convertir el sueño en acción, bajo esquemas de interdependencia. Puntos claves en un liderazgo centrado en la persona humana.

Cabe preguntarse, ¿qué es lo que el yo debe dar para llegar hasta el tú? El verdadero líder está en capacidad de darse desde la plenitud de su ser (Barroso, 1987), de darse a sí mismo, su persona, en lo que tiene de más profundo e insustituible pero esta donación no es fácil pues el yo no puede ser sustituido de la misma forma que pueden ser reemplazadas las cosas y no se da lo que no se posee, por lo tanto para darse primero que nada el líder debe poseerse, ser dueño de sí mismo. Debe presentarse al otro como en realidad es, con sus aspectos positivos y negativos, como se mencionó anteriormente consciente de sus posibilidades y seguro de que con la ayuda del otro puede hacer realidad el futuro que desea construir, al mismo tiempo que ayuda al otro a hacer realidad el suyo.

En la modernidad el "yo" se fija en el "tú" como cosa. En la postmodernidad el "yo" sigue sin reconocer al "tú", pero empieza a ver en él alguien que construye y que podría serle útil para alcanzar sus objetivos. En contraste, Juan XXIII (1963:235) expresa "La experiencia en- 
Modernismo y postmodernismo, hacia la construcción de un liderazgo antropocéntrico Mendoza de Ferrer, Hermelinda

seña que son muchas y muy grandes las diferencias entre los hombres en ciencia, virtud, inteligencia y bienes materiales. Sin embargo, este hecho no puede justificar nunca el propósito de servirse de la superioridad propia para someter de cualquier modo a los demás. Todo lo contrario: esta superioridad implica una obligación social mas grave para ayudar a los demás a que logren, con esfuerzo común, la perfección propia".

Hace falta pues, comenzar a descubrir en el "tu" otro "yo" autónomo y responsable como uno, con defectos y cualidades como uno, pero no necesariamente los propios, ya que, cada uno es único e irrepetible. Para lograrlo es necesario superar, en las relaciones interpersonales, la indiferencia, el interés manipulador, la proyección narcisista y la rivalidad. Sólo así el otro aparecerá "no como algo, sino como alguien no rival y enemigo, sino como amigo" (Hortelano, 1989:146), actitud a seguir por el líder, según los autores referenciados.

Ahora bien, el verdadero nosotros no puede existir si, a la entrega generosa del "yo", no hay una respuesta semejante del "tu". Sólo a base de reciprocidad puede darse un auténtico nosotros, por lo cual el esfuerzo tiene que ser de ambas partes, donde el yo y el tu ejercen una influencia recíproca el uno sobre el otro que no tiene por objeto comunicar las propias riquezas sino ayudar a descubrir las del otro. "Para ejercer sobre el tú esa influencia discreta y olvidada de sí, se requiere un gran desinterés, un despojarse sin medida de todo amor propio...Esto es mucho más difícil, sin duda alguna, que dar a los demás lo que uno ya ha adquiri- do o descubierto por sí mismo" (Hortelano, 1989:149).

En este tipo de relación, el diálogo vendría a ser la puesta en común de "la visión que el yo y el tu tienen del mundo y de la vida. El yo presta los ojos al tú con todo lo que él ha visto con ellos y el tú hace lo mismo con los suyos prestándoselos al yo. De este modo el yo y el tú, no solamente ven más cosas y amplían así su campo de visión, sino sobre todo ven el mundo en una nueva dimensión. Su mirada adquiere una mayor profundidad que les permite contemplar nuevos horizontes" (Hortelano, 1989:150). Esta apertura desencadena un dinamismo que amplia en cadena las relaciones con los demás: yo, pareja, equipo, comunidad, sociedad y cosmos. Sin embargo, es oportuno destacar que este modelo de liderazgo sólo se posibilita mediante aproximaciones que, al igual que la paz nunca será cosa del todo hecha, sino un perpetuo quehacer.

\section{Referencias Bibliográficas}

Aguiar, Asdrúbal (2000). Cultura de Paz y Derechos Humanos. Caracas: UNESCO Publicaciones UCAB.

Appignanesi, Richard y otros (1995). Posmodernismo para Principiantes. Buenos Aires: Era Naciente, S.R.L.

Barroso, Manuel (1987). Autoestima Ecología o Catástrofe. Caracas: Editorial Galac, S.A.

Chaves, Carmen (1999). El Debate Teórico Actual. En Más Allá de la Pos-modernidad. El Discurso Antrópico y su Praxis en la Cultura Iberoamericana. de José Luis Díaz- Martínez. Madrid: Mileto. Disponible en http://www.ensayo.rom.uga.edu.crítica/teoría. [Consulta 2005, Diciembre 14]. 
Chen, Wang (2000). El Tao de la Paz. El Arte de manejar la Dinámica de los Conflictos. (Versión y comentarios de Ralph Sawyer).México: EDAF, S.A.

Conger, Jay (1991). El líder Carismático. Liderazgo Carismático: Un Modelo para Desarrollar Cambios Organizacionales Exitosos. Bogot: Mac Graw-Hill Interamericana, S.A.

De La Garza, Enrique; Celis, Juan; Olivo, Miguel y Retamozo, Martín (2008). "Crítica de la Razón Para-Postmoderna (Senté, Bauman, Beck)". Revista Latinoamericana de Estudios del Trabajo. Segunda época. Año 13, No 19, 2008. Disponible en http://servicio. cid.uc.edu.ve [Consulta, Septiembre, 12 de 2008]

Gaudium Et Spes (1966). Constitución Pastoral sobre la Iglesia en el Mundo Actual. En Concilio Vaticano II. Constituciones. Decretos. Declaraciones. Documentos Pontificios Complementarios. Madrid: Biblioteca de Autores Cristianos.

Gergen, Kenneth y Tojo, Joseph (1996). Organizational Science in Postmoderm Context, Draft Copy for Journal of Applied Behavorial Science $N^{\circ} 32, p p$ 356-377.

Gergen, Kenneth y Tojo, Joseph (2004). Organization Science as Social Construction: Postmodern Potential. Journal of Applied Behavioral Science, Jun 2004; 40: 228 - 249. Disponible en http://jab.sagepub.com/ [Consulta, 2006, Diciembre 10]

Gómez-Martínez, José (1999). Más Allá de la pos-modernidad. El Discurso Antrópico y su Praxis en la Cultura Iberoamericana. Madrid: Mileto Disponible en http://www.ensayo.rom. uga.edu/crítica/teoría/gómez4h.ht. [Consulta, 2005, Diciembre, 14]

Hortelano, Antonio (1989). Moral de Bolsillo. Salamanca, España: Editorial Sígueme.
Hunter, James (1999). La Paradoja. Un Relato de la Verdadera esencia del Liderazgo. Barcelona España: Ediciones Urano, S.A.

Juan Pablo II (2000). Carta Apostólica Tertio Millennio Adveniente del sumo pontífice Juan Pablo II al Episcopado, al Clero y a los fieles como preparación del jubileo del año 2000. Caracas: Ediciones Trípode

Juan XXIII (1963). Pacem in Terris Carta Encíclica sobre la Paz entre Todos los pueblos, que ha fundarse en la Verdad, la Justicia, el Amor y la libertad. Disponible http://www.ecologia.social.org/doctrina.asp [Consulta 2005, Noviembre 11]

Juárez, José (2005). “¿Que Tipo de Líderes para cuál Sociedad?". Revista Educación en Valores. Año 2. Vol. 2. N4. Valencia, Julio-Diciembre 2005 PP 15-25. Disponible http://www.oei.es/ n11009.htm [Consulta, 2008, Septiembre, 04]

Kets De Vries Manfred y Florent-treacy, Elizabeth (1999). Los Nuevos Líderes Globales. Lecciones para Enfrentar el Futuro y Transformar Empresas en Organizaciones Globales de Primer Orden. Bogotá: Norma.

Kunt, Tomas (1971). La Estructura de las Revoluciones Científicas. Fondo de Cultura Económica. Santa Fe de Bogotá.

Lanz, Rigoberto (Comp.). (2001). Organizaciones Transcomplejas. Caracas, IMPOSMO-CONICIT.

Light, Donald y otros (1991). Sociología. Santa Fe de Bogotá: MacGraw-Hill Hispanoamericana.

López, Frank (2001). “Del Comportamiento Organizacional a la Práctica de Producción del Sentido". En R. Lanz (Comp.), Organizaciones Transcomplejas (pp. 97-144). Caracas, IMPOSMOCONICIT. 
Modernismo y postmodernismo, hacia la construcción de un liderazgo antropocéntrico Mendoza de Ferrer, Hermelinda

Márquez, María del Valle (2001). "Nuevas Tecnologías. Nuevas Organizaciones. Nuevos Aprendizajes". En Lanz, R. (Comp.), Organizaciones Transcomplejas (pp. 177-194). Caracas, IMPOSMO-CONICIT.

Mendoza de Ferrer, Hermelinda y Rodríguez, María (2007). "La Teoría Administrativa en el Contexto Emergente". Contaduría y Administración. Nueva Época Arbitrada. $\mathrm{N}^{\circ}$ 223. Facultad de Contaduría y Administración, Universidad Nacional Autónoma de México, D.F. Septiembre-Diciembre, 2007.

Mendoza de Ferrer, Hermelinda (2007). "Esquema Conceptual para el Desarrollo de líderes Operacionales". Revista de Ciencias Sociales (RCS) Vol. XII, No 1, Enero-Abril 2007, pp. 47-58. FACES-LUZ. Maracaibo.

Meszaros, Esteban (2006). "Paradigmas para el Líder del Nuevo Milenio: la Cultura de la Paz y la Construcción de una Sociedad más Sana y Fraternal". Revista Educación en Valores, Año 3. Vol. 1. No. 5. Valencia, Enero - Junio 2006. Disponible http://www.oei. es/n11009.htm [Consulta, 2008, Septiembre, 04]

Pérez, José (2007). Del Bienestar a la Justicia. Aportaciones para una Ciudadanía Intercultural. Madrid: Editorial Trotta.

Robbins, Stephen (2004). Comportamiento Organizacional. México: Pearson Prentice Hall.
Ritzer, George (1993). Teoría Sociológica Clásica. Madrid: MacGraw-Hilll Interamericana de España, S.A.

Schvarstein, Leonardo (1998). Diseño de Organizaciones. Tensiones y Paradojas. Buenos Aires, Argentina: PAIDOS.

Senge, Peter y otros (2000). La Danza del Cambio, los Retos de Sostener el Impulso en Organizaciones Abiertas al Aprendizaje. Santa Fe de bogota, CoIombia: Editorial Norma S.A.

Swieringa Joop, y Wierdsma, André (1995). La Organización que Aprende. Madrid: Addison-Wesley Iberoamericana.

Ulrich, Dave y otros (1999). Liderazgo Basado en Resultados. De cómo los Líderes Fortalecen el Negocio e Incrementan las Utilidades. Bogotá: Harvard Business Shool Press. Grupo Editorial Norma.

Val Pardo, Isabel de (1998). "Modernidad y Postmodernidad del Diseño Organizativo". En Agueda, E., y otros. Principios de Marketing. Madrid: ESIC EDITORIAL.

Zambrano, Luisa (2001). "Las Organizaciones Modernas: Lógicas en Transfiguración". En Lanz, R. (Compilador). Organizaciones Transcomplejas. IMPOSMO / CONICIT: Caracas.

Zamora, Angel y Yenitza Poriet (2006). "Papel de los Líderes y Nuevas Tendencias del Liderazgo en el Siglo XXI". Revista FACES. Vol. XVII - Número 1. Enero - Junio 2006. 